\title{
Pathologic Stage 0 Esophageal Squamous Cell Carcinoma AJCC v8
}

National Cancer Institute

\section{Source}

National Cancer Institute. Pathologic Stage O Esophageal Squamous Cell Carcinoma AJCC v8. NCI Thesaurus. Code C133519.

Stage 0 includes: Tis, NO, M0, GN/A, T umor location: Any. T is: High-grade dysplasia, defined as malignant cells confined to the epithelium by the basement membrane. N0: No regional lymph node metastasis. M0: No distant metastasis. GN/A: Grade nonapplicable. (AJCC 8th ed.) 